\title{
AVALIAÇÃO DO IMPACTO DE PRÉ-TRATAMENTOS SOBRE A EXTRAÇÃO DE CAROTENÓIDES POR PRENSAGEM SEQÜENCIAL DE BAGAÇO DE CAJU
}

\author{
HENRIETTE M.C. AZEREDO* \\ FERNANDO A.P. ABREU** \\ LOUISE L. SOUSA*** \\ ARTHUR C.R. SOUZA**** \\ EDY S. BRITO*****
}

\begin{abstract}
A extração de carotenóides ocorre geralmente por solventes orgânicos, cujos impactos negativos incentivam sua substituição por processos de prensagem, utilizando água como solvente. A baixa solubilidade dos carotenóides em água pode ser parcialmente compensada por pré-tratamentos que hidrolisem ou rompam as paredes celulares dos tecidos, como congelamento e tratamento enzimático. O objetivo deste trabalho foi avaliar o efeito do congelamento do bagaço de caju (subproduto da produção de suco) e da ação da pectinase sobre a extração de carotenóides por prensagem. $O$ bagaço do caju, previamente congelado ou não, foi macerado em água ou solução de pectinase, prensado e filtrado, gerando o extrato. $O$ bagaço resultante do primeiro ciclo maceração-prensagem passou por mais quatro ciclos, sendo a maceração sempre em água. Os teores de carotenóides do bagaço e dos extratos obtidos de cada ciclo foram analisados. A eficiência da extração de carotenóides tendeu a diminuir ao longo do número de ciclos. Tanto o congelamento quanto o tratamento enzimático aumentaram significativamente a eficiência global do processo de extração, especialmente o primeiro.
\end{abstract}

\section{PALAVRAS-CHAVE: EXTRAÇÃO AQUOSA; ENZIMAS; PECTINASE; BAGAÇO DE CAJU.}

Engenheira de Alimentos, doutora em Tecnologia de Alimentos, pesquisadora da EMBRAPA Agroindústria Tropical, Fortaleza CE (e-mail:ette@cnpat. embrapa.br).

** Engenheiro de Alimentos, mestre em Tecnologia de Alimentos, EMBRAPA Agroindústria Tropical, Fortaleza, CE (e-mail: abreu@cnpat.embrapa.br).

*** Graduanda em Engenharia Química, Universidade Federal do Ceará, Forta leza, CE (e-mail: louise_lins@yahoo.com.br).

**** Engenheiro Civil, EMBRAPA Agroindústria Tropical, Fortaleza, CE (e-mail: arthur@cnpat.embrapa.br).

Químico, doutor em Tecnologia de Alimentos, pesquisador da EMBRAPA

Agroindústria Tropical, Fortaleza, CE (e-mail: edy@cnpat.embrapa.br). 


\section{INTRODUÇÃO}

A agroindústria do caju tem gerado muitos empregos na região Nordeste do Brasil, especialmente no Estado do Ceará que conta com setor industrial muito desenvolvido para o processamento da castanha. Entretanto, o pedúnculo do caju ainda é amplamente desperdiçado. A produção do suco de caju, mediante prensagem dos pedúnculos, gera como subproduto o bagaço, normalmente descartado ou utilizado para elaboração de ração animal. No entanto, o bagaço de caju constitui fonte de carotenóides (um dos grupos de pigmentos mais abundantes na natureza), utilizados como corantes naturais em alimentos (RODRIGUEZ-AMAYA, 1984).

A exploração de fontes de corantes naturais assume importância na indústria de alimentos porque a cor desperta o interesse do consumidor, desenpenhando papel mercadológico. A manutenção da cor natural de alimentos pode ser dificultada pelo processamento, que resulta freqüentemente em degradação de pigmentos e exige a adição de corantes. Os corantes sintéticos, embora mais baratos e mais estáveis quimicamente, enfrentam resistência por parte dos consumidores e preocupam os pesquisadores da área de alimentos. A substituição de corantes sintéticos por naturais também encontra obstáculos, devido seu alto custo e falta de fontes abundantes (BOBBIO e BOBBIO, 2001).

Várias funções biológicas têm sido atribuídas aos carotenóides, como a comprovada atividade de pró-vitamina $A$ de alguns desses pigmentos, especialmente do beta-caroteno. Adicionalmente, estudos têm indicado efeitos quimiopreventivos dos carotenóides associados com suas propriedades antioxidantes e não de pró-vitamina A. Tais estudos indicam relação negativa entre a ingestão de carotenóides e a ocorrência de diversas doenças degenerativas como, câncer, doenças cardiovasculares e catarata, entre outras (CRAMER et al., 2001; DE STEFANI et al., 2002; GALE et al., 2001; MAOKA et al., 2001).

A extração de pigmentos de tecidos vegetais, especialmente de pigmentos hidrofóbicos (como os carotenóides), ocorre geralmente com a da utilização de solventes orgânicos. No entanto, são conhecidos os impactos negativos de diversos desses solventes sobre o ambiente e a saúde humana. O fato de muitos solventes orgânicos emitirem gases poluentes e/ou carcinogênicos motivou a realização de pesquisas sobre a substituição da extração com solventes orgânicos 
por processos mais "limpos", ambientalmente, e que não promovam danos à saúde (ROSENTHAL, PYLE e NIRANJAN, 1996). Os carotenóides poderiam ser extraídos, por exemplo, por maceração dos tecidos em meio aquoso seguida por prensagem. A principal limitação da extração aquosa de carotenóides envolve sua baixíssima solubilidade em água. Alguns métodos têm sido sugeridos para superar a limitação da extração aquosa de compostos com baixa polaridade. Entre esses métodos destaca-se a utilização de enzimas, considerando que os carotenóides estão contidos nas células e que as paredes celulares têm estruturas complexas. O uso de enzimas com atividades mistas (celulase, hemicelulase e pectinase, principalmente), que hidrolisam os polissacarídeos estruturais das paredes celulares dos tecidos, favorece a liberação de seu conteúdo que inclui os pigmentos (DOMINGUEZ, NÚÑEZ, e LEMA, 1994; DELGADO-VARGAS, JIMÉNEZ e PAREDES LÓPEZ, 2000).

Muitos trabalhos têm enfocado processos aquoso-enzimáticos para extração de óleos vegetais. No entanto, são raros os registros de aplicação dessa tecnologia para extração de pigmentos. O précongelamento dos tecidos também pode aumentar a eficiência da extração, já que resulta em ruptura de estruturas celulares facilitando a liberação de seu conteúdo. A EMBRAPA (2001) desenvolveu método para liberação de pigmentos a partir de bagaço de pedúnculo de caju, envolvendo a seqüência de extrações aquosas. No entanto, a eficiência das diferentes etapas de extração e o impacto dos pré-tratamentos do bagaço não foram quantificados.

O objetivo deste trabalho foi avaliar o impacto do congelamento do bagaço de caju e da adição de pectinase sobre a eficiência de etapas seqüenciais de extração de carotenóides por prensagem.

\section{MATERIAL E MÉTODOS}

Os pedúnculos de caju CCP-076, produzidos no Campo Experimental de Paraipaba da Embrapa Agroindústria Tropical, foram lavados e sanitizados com solução contendo $50 \mathrm{mg} / \mathrm{L}$ de cloro ativo. A extração do suco ocorreu em prensa tipo expeller, seguida por filtração do suco em peneira de $3 \mathrm{~mm}$. A extração gerou o bagaço como subproduto, que foi submetido a quatro tratamentos alternativos (realizados em 3 repetições). O primeiro tratamento $(A)$ incluiu maceração do bagaço por 1 hora em solução aquosa a 1000 mg/kg 
do preparado enzimático Pectinex® Ultra SPL (Novozymes), que além da pectinase tem atividades de celulase e hemicelulase (NOVOZYMES, 2005). O segundo tratamento (B) envolveu o congelamento do bagaço a $-18^{\circ} \mathrm{C}$, seguido de maceração por 1 hora em solução aquosa a $1000 \mathrm{mg} / \mathrm{kg}$ de Pectinex. O terceiro tratamento (C) consistiu na maceração do bagaço por 1 hora em água e o quarto (D) no congelamento do bagaço $\mathrm{a}-18^{\circ} \mathrm{C}$, seguido de maceração por 1 hora em água.

A temperatura da água ou da solução enzimática utilizada para maceração foi de $27^{\circ} \mathrm{C}$ pela proximidade com $30^{\circ} \mathrm{C}$, considerada temperatura ótima de ação de pectinase da enzima (BAILEY e PESSA, 1990).

Manteve-se a proporção mássica bagaço: solução enzimática ou bagaço: água de 1:1. Para cada tratamento, o bagaço macerado foi então prensado em expeller e filtrado em peneira de $3 \mathrm{~mm}$. Desse primeiro ciclo maceração-prensagem-filtração resultou o extrato 1 (filtrado). O subproduto dessa prensagem passou por mais quatro ciclos seqüenciais maceração-prensagem-filtração. A maceração, nesses ciclos, foi sempre em água (independentemente do tratamento) na proporção mássica 1:1 (bagaço: água) e tempo de maceração de 5 minutos. O bagaço e os extratos de 1 a 5 (obtidos da primeira até a quinta extração) foram analisados quanto aos teores de carotenóides totais (HIGBY, 1962) para estimar e comparar a eficiência da extração de carotenóides (EEC) pelos diferentes tratamentos (equação 1). $O$ valor EEC refere-se ao percentual da massa de carotenóides contidos no bagaço inicial que foram extraídos em determinada etapa de extração. Para cada tratamento foram realizados testes de Tukey $(p<0,05)$ para comparar a eficiência das diferentes extrações (ZAR, 1998). As eficiências globais, definidas como as somas dos valores de EEC para cada tratamento, foram também comparadas pelo teste de Tukey.

$$
E E C_{n}(\%)=\frac{C T_{n} \times m_{n}}{C T_{b 0} \times m_{b 0}} \times 100
$$

Na qual:

$E E C_{n}=$ eficiência da extração de carotenóides pela n-ésima etapa de extração $(1 \leq n \leq 5)$;

$C T_{n}=$ teor de carotenóides totais do extrato obtido a partir da n-ésima etapa;

$m_{n}=$ massa do extrato resultante da n-ésima etapa;

$C T_{b 0}=$ teor de carotenóides totais do bagaço inicial;

$m_{b 0}=$ massa do bagaço inicial. 


\section{RESULTADOS E DISCUSSÃO}

O bagaço de pedúnculo de caju continha concentração inicial de carotenóides de $27 \mathrm{mg} / \mathrm{kg}$. A Tabela 1 apresenta os valores de EEC das diferentes etapas de extração do bagaço do caju, assim como as eficiências globais de cada tratamento. Para cada tratamento, os valores de EEC tenderam a diminuir ao longo das extrações porque os bagaços resultantes de cada extração tornavam-se progressivamente mais pobres em carotenóides. No caso do tratamento $\mathrm{B}$, submetido tanto ao congelamento quanto ao tratamento enzimático, a diferença entre a primeira extração e as demais foi especialmente marcante. Tal fato sugere que a primeira extração foi bastante facilitada pela combinação de ambas as técnicas. A comparação entre as eficiências globais de cada tratamento indicou que o congelamento e o tratamento enzimático aumentaram significativamente a eficiência de extração de carotenóides, sendo o efeito do congelamento maior que o do tratamento enzimático. Mesmo o tratamento $B$, submetido a ambas as técnicas, não extraiu sequer $50 \%$ dos carotenóides contidos no bagaço inicial. Tal resultado sugere a necessidade de se buscar outras técnicas que auxiliem a extração por prensagem aquosa de carotenóides.

\section{TABELA 1 - EFICIÊNCIA DA EXTRAÇÃO DE CAROTENÓIDES DAS DIFERENTES ETAPAS DE EXTRAÇÃO DO BAGAÇO DOCAJU}

\begin{tabular}{|c|c|c|c|c|}
\hline \multirow{3}{*}{ Extração } & \multicolumn{4}{|c|}{ EEC (\%) } \\
\hline & \multicolumn{4}{|c|}{ Tratamentos } \\
\hline & A & B & $\mathrm{C}$ & $\bar{D}$ \\
\hline 1 & $7,93 \mathrm{a}$ & $20,20 a$ & $4,52 \mathrm{a}$ & $8,24 a$ \\
\hline 2 & $5,58 b$ & $7,16 \mathrm{~b}$ & $4,26 \mathrm{~b}$ & $8,05 a b$ \\
\hline 3 & $5,85 b$ & $6,65 b$ & $4,27 b$ & $7,74 \mathrm{~b}$ \\
\hline 4 & $5,24 \mathrm{bc}$ & $6,69 \mathrm{~b}$ & $4,03 \mathrm{c}$ & $6,52 c$ \\
\hline 5 & $4,97 \mathrm{c}$ & $6,02 \mathrm{~b}$ & $3,89 \mathrm{~d}$ & $5,36 d$ \\
\hline Eficiências globais & $29,57 \mathrm{C}$ & $46,72 \mathrm{~A}$ & $20,97 \mathrm{D}$ & 35,91 B \\
\hline
\end{tabular}

$A=$ maceração em solução enzimática; $B$ = congelamento seguido de maceração em solução enzimática; $C$ = maceração em água; $D$ = congelamento seguido de maceração em água.

Os valores consistem em médias de 3 repetições.

Valores na mesma coluna seguidos pela mesma letra (minúscula) não diferem significativamente entre si $(p<0,05)$.

Valores de eficiências globais seguidos pela mesma letra (maiúscula) não diferem entre si $(p<0,05)$. 
O efeito da ação enzimática confirmou os resultados obtidos por DELGADO-VARGAS e PAREDES-LÓPEZ (1997), que registraram melhores extrações de carotenóides em amostras tratadas com enzimas do que maceradas simplesmente em água. São mais comuns os trabalhos tratando de extração aquosa de óleos vegetais e dentre esses, vários registraram melhor eficiência da extração em decorrência de tratamento enzimático (BUENROSTRO e LOPEZMUNGUIA, 1986; BARRIOS et al., 1990; YOON, KIM e KWON, 1991; ZÚÑIGA et al., 2003).

\title{
4 CONCLUSÃO
}

Tanto o congelamento quanto o tratamento enzimático promoveram maior eficiência da extração aquosa de carotenóides do bagaço do pedúnculo de caju, especialmente o congelamento. A eficiência da extração de carotenóides diminuiu conforme o aumento do número de prensagens. A maior eficiência de extração de carotenóides (46,7\%) foi obtida mediante combinação entre o congelamento do bagaço e o tratamento enzimático.

\section{Abstract \\ EVALUATION OF THE IMPACT OF PRETREATMENTS ON CAROTENOID EXTRACTION BY SEQUENTIAL PRESSING OF CASHEW APPLE POMACE}

\begin{abstract}
Carotenoid extraction is usually carried out by using organic solvents, whose negative impacts have motivated attempts to replace this kind of extraction by pressing processes, using water as solvent. The low water solubility of carotenoids may be partially counterbalanced by pre-treatments that hydrolyze or disrupt the cell walls, such as freezing and enzyme treatment. The objective of this work was to evaluate the effects of freezing and pectinase treatment of cashew pomace (byproduct of cashew juice processing) on carotenoid extraction by pressing. The cashew pomace, previously freezed or not, was macerated in water or pectinase solution, it was then pressed and filtered, producing an extract. The pomace resulting from the first maceration-pressing cycle was submitted to four further cycles, all the macerations being in water. The total carotenoid contents of the pomace and the extracts obtained from each cycle were determined. The efficiency of carotenoid extraction tended to decrease with number of cycles. Both freezing and enzyme treatment increased the overall efficiency of extraction, especially the first one.
\end{abstract}

KEY-WORDS: AQUEOUS EXTRACTION; ENZYMES; PECTINASE; CASHEW APPLE POMACE. 


\section{REFERÊNCIAS}

1 EMBRAPA. Embrapa Agroindústria Tropical (Fortaleza). ABREU, Fernando Antonio Pinto de. Extrato de bagaço de caju rico em pigmento. BR. n. PI 0103885-0, 19 jun. 2001.

2 BAILEY, M.J.; PESSA, E. Strain and process for production of polygalacturonase. Enzyme Microbiol. Technol., Atlanta, v. 12, p. 266-71, 1990.

3 BARRIOS, V.A.; OLMOS, D.A.; NOYOLA, R.A.; LOPEZMUNGUIA, C.A. Optimization of an enzymatic process for coconut oil extraction. Oleagineux, v. 45, p. 35-42, 1990.

4 BOBBIO, P.A.; BOBBIO, F.O. Química do processamento de alimentos. 3. ed. São Paulo: Varela, 2001. p. 103-118.

5 BUENROSTRO, M.; LOPEZ-MUNGUIA, C.A. Enzymatic extraction of avocado oil. Biotechnology Letters, v. 8, p. 505$506,1986$.

6 CRAMER, D.W.; KUPER, H.; HARLOW, B.L.; TITUS-ERNSTOFF, L. Carotenoids, antioxidants and ovarian cancer risk in pre- and postmenopausal women. Int. J. Cancer, Heidelberg, v. 94, n. 1, p. 128-134, 2001.

7 DELGADO-VARGAS, F.; JIMÉNEZ, A.R.; PAREDES-LÓPEZ, O. Natural pigments: carotenoids, anthocyanins and betalains characteristics, biosynthesis, processing, and stability. Crit. Rev. Food Sci. Nutr., Amherst, v. 40, n. 3, p. 173-289, 2000.

8 DE STEFANI, E.; BRENNAN, P.; BOFFETTA, P.; MENDILAHARSU, M.; DENEO-PELLEGRINI, H.; RONCO, A.; OLIVERA, L.; KASDORF, H. Diet and adenocarcinoma of the lung: a case-control study in Uruguay. Lung Cancer, Copenhagen, v. 35, n. 1, p. $43-51,2002$.

9 DELGADO-VARGAS, F.; PAREDES-LÓPEZ, O. Effects of enzymatic treatments on carotenoid extraction from marigold flowers (Tagetes erecta). Food Chem., v. 58, n. 3, p. 255-258, 1997.

10 DOMINGUEZ, H.; NÚÑEZ, M.J.; LEMA, J.M. Enzymatic 
pretreatment to enhance oil extraction from fruits and oilseeds: a review. Food Chem., Reading, v. 49, p. 271-286, 1994.

11 DOMINGUEZ, H.; NÚÑEZ, M.J.; LEMA, J.M. Enzyme-assisted hexane extraction of soya bean oil. Food Chem., v. 54, n. 2, p. 223-231, 1995.

12 GALE, C.R.; HALL, N.F.; PHILLIPS, D.I.W.; MARTIN, C.N. Plasma antioxidant vitamins and carotenoids and age-related cataract. Ophtalmol., Philadelphia, v. 108, n. 11, p. 1992-1998, 2001.

13 HIGBY, W.K. A simplified method for determination of some thecarotenoid distribution in natural and carotene-fortified orange juice. J. Food Sci., Chicago, v.27, p.42-49, 1962.

14 MAOKA, T. et al. Cancer chemopreventive activity of carotenoids in the fruits of red paprika Capsicum annuum L. Cancer Letters, Heidelberg, v. 172, n. 2, p. 103-109, Out. 2001.

15 NOVOZYMES. Pectinex Ultra SP-L. Disponível em: <http:// www.novozymes.com/cgi-bin/bvisapi.dll/solutions/ solutions.jsp?cid=-11568\&id=30508>. Acesso em: 02 fev. 2005.

16 RODRIGUEZ-AMAYA, D.B. Carotenóides. In: RODRIGUEZAMAYA, D.B.; BOBBIO, F.O.; BOBBIO, P.A. Curso sobre pigmentos naturais. Campinas: SBCTA, 1984. p. 31-56.

17 ROSENTHAL, A.; PYLE, D.L.; NIRANJAN, K. Aqueous and enzymatic processes for edible oil extraction. Enzyme Microb. Technol., Atlanta, v. 19, n. 6, p. 402-420, 1996.

18 YOON, S. H.; KIM, I. H.; KWON T. W. Effect of enzyme treatment and ultrasonification on extration yields of lipids and protein from soybean by aqueous process. Korean J. Food Sci. Technol., v. 23, p. 673-676, 1991.

19 ZAR, J.H. Biostatistical analysis. $4^{\text {th }}$ ed. New York: Prentice Hall, 1998. $929 \mathrm{p}$.

20 ZÚÑIGA, M.E.; SOTO, C.; MORA, A.; CHAMY, R.; LEMA, J.M. Enzymic pre-treatment of Guevina avellana mol oil extraction by pressing. Process Biochem., v. 39, n. 1, p. 51-57, 2003. 